\title{
Assessment of the quality of fall detection and management in primary care in the Netherlands based on the ACOVE quality indicators
}

\author{
M. Askari ${ }^{1}$ - S. Eslami ${ }^{1}$ - M. van Rijn ${ }^{2}$ - S. Medlock ${ }^{1}$ - E. P. Moll van Charante ${ }^{3}$. \\ N. van der Velde $^{2} \cdot$ S. E. de Rooij ${ }^{2}$ A. Abu-Hanna ${ }^{1}$
}

Received: 20 May 2014 / Accepted: 2 July 2015 / Published online: 21 July 2015

(C) The Author(s) 2016. This article is published with open access at Springerlink.com

\begin{abstract}
Summary We determined adherence to nine fall-related ACOVE quality indicators to investigate the quality of management of falls in the elderly population by general practitioners in the Netherlands. Our findings demonstrate overall low adherence to these indicators, possibly indicating insufficiency in the quality of fall management. Most indicators showed a positive association between increased risk for functional decline and adherence, four of which with statistical significance.

Introduction This study aims to investigate the quality of detection and management of falls in the elderly population by general practitioners in the Netherlands, using the Assessing Care of Vulnerable Elders (ACOVE) quality indicators. Methods Community-dwelling persons aged 70 years or above, registered in participating general practices, were asked to fill in a questionnaire designed to determine general practitioner (GP) adherence to fall-related indicators. We used logistic regression to estimate the association between increased risk for functional decline - quantified by the Identification of Seniors At Risk for Primary Care score - and adherence. We then cross-validated the self-reported falls with medical records.
\end{abstract}

A. Abu-Hanna

a.abu-hanna@amc.uva.nl

1 Department of Medical Informatics, Academic Medical Center, University of Amsterdam, Amsterdam, The Netherlands

2 Department of Internal Medicine, Section of Geriatric Medicine, Academic Medical Center, University of Amsterdam, Amsterdam, The Netherlands

3 Department of General Practice, Academic Medical Center, University of Amsterdam, Amsterdam, The Netherlands
Results Of the 950 elders responding to our questionnaire, only $10.6 \%$ reported that their GP proactively asked them about falls. Of the 160 patients who reported two or more falls, or one fall for which they visited the GP, only $23.1 \%$ had fall documentation in their records. Adherence ranged between 13.6 and $48.6 \%$. There was a significant positive association between the ISAR-PC scores and adherence in four QIs. Documentation of falls was highest (36.7 \%) in patients whom the GP had proactively asked about falls.

Conclusion Based on patient self-reports, adherence to the ACOVE fall-related indicators was poor, suggesting that the quality of evaluation and management of falls in communitydwelling older persons in the Netherlands is poor. The documentation of falls and fall-related risk factors was also poor. However, for most QIs, adherence to them increased with the increase in the risk of functional decline.

Keywords Elderly · Fall detection · Primary care · Quality indicators · Quality of care

\section{Introduction}

Falls in older age pose a major health concern since they occur frequently and have serious consequences for both the elderly individuals and the healthcare system in terms of costs and psychological and medical attention [1-4]. Currently, over 20 fall risk factors have been identified, and usually falling is associated with the presence of multiple risk factors $[3,5,6]$. In addition, interactions between different risk factors such as old age, having a history of falling, multimorbidity, and the use of certain medications may have an additive effect to the risk of falling [7-9].

Despite the complex nature of the falls, many of its risk factors and their interactions are modifiable, thus providing 
opportunities for prevention, treatment, and management [10]. Promising interventions, guidelines, and strategies for detecting community-dwelling seniors, at an increased risk of falling and subsequently reducing the number of recurrent falls, have been developed [11-15]. However, fall prevention programs often involve multiple healthcare professionals, and lack of effective communication and coordination between them may lead to under-detection and loss of attention to falls [16]. In a previous study, we showed lacunas in the role that general practitioners (GPs) currently play in fall detection and prevention in a large shared care case study in the Netherlands [16]. In addition, older seniors often do not complain to physicians about fall-related problems, such as decreased balance and mobility, and therefore falls may go undetected and untreated until after an otherwise preventable injury has occurred [17].

The Assessing Care Of Vulnerable Elders (ACOVE) quality indicators (QIs) is a set of indicators in the form of rules intended to evaluate whether the care being delivered to (vulnerable) elderly meets prespecified quality standards. In this paper, we use the terms quality indicator and rule interchangeably. The higher the adherence to the rules, the better the quality of delivered care is [18]. Adherence to a rule is quantified as the "pass rate" of the rule, which is the proportion of times the rule was actually followed when it should have been followed. The ACOVE QIs are based on evidence and expert opinion and describe process rather than outcome measures. This set comprises 12 QIs pertaining to fall detection and management, which forms a promising tool to assess fall-related quality of care. In particular, the population of seniors at increased risk of health deterioration forms an important target for quality of care assessment and intervention [19].

In a recent systematic review [11], we showed that the quality of fall detection and management in primary care, nursing homes, and managed care was low, based on ACOVE-based quality indicators, with pass rates varying from 3 to $44 \%$.

To our knowledge, there are no studies investigating fall detection and management by general practitioners in Europe using a comprehensive set of ACOVE fall QIs. Therefore, the aim of our study was to assess the quality of detection and management of falls in the elderly population by general practitioners in the Netherlands, by using all ACOVE fall-related QIs which were selected by a team of experts, including GPs themselves, for the Dutch setting (9 out of the original 12). In addition, we investigated the association between adherence to the QIs and the functional state of the patient. We also validated the self-reported falls against the information recorded in the patients' electronic medical records.

\section{Method}

\section{Study design and population}

Twenty GPs in four primary healthcare centers participated in our study. These GPs were registered at a network of practices in Amsterdam Southeast called the GAZO centers (Gezondheidscentra ZuidOost) and were using the same electronic medical record (EMR). All community-dwelling persons aged 70 years or older registered in any one of the participating general practices were identified through the EMR by their GP. Exclusion criteria were terminal illness, dementia, insufficient understanding of Dutch, or plans to move or spend a long time abroad. Eligible persons received a letter with study information from their GP, along with a written informed consent form, a self-reporting questionnaire and a return envelope. They were invited to fill out the questionnaire themselves, but if they needed help, an informal caregiver was allowed to provide help.

\section{Ethical approval and informed consent}

All participants were asked to provide written informed consent for data collection and participation in the study after receiving written study information. The study was part of a larger study and was approved by the Medical Ethics Committee of the Academic Medical Center, University of Amsterdam, in the Netherlands (protocol FIT: MEC10/182) [20].

\section{Fall quality indicator set}

A total of 108 ACOVE QIs covering eight conditions, including falls, were previously translated to the Dutch GP setting by a panel of nine clinical experts in The Netherlands. This translated set contains 9 (out of the original 12) fall-related QIs, which we used in the current study for assessing the quality of fall detection and prevention by GPs $[12 ; 18]$.

The QIs focus on screening for falls and instability, and on the approach to manage and document these conditions. A QI is formulated as a rule linking a logical condition to a conclusion. An example of a rule is "IF a vulnerable elder reports a history of two or more falls (or one fall for which the elder visits the general practitioner) in the past year, THEN the general practitioner should document a basic fall history (including type and circumstances of the falls and possible contributing factors) within 3 months of the reported history". A rule is adhered to if the conclusion (which is an action) is fulfilled when its condition was true.

\section{Survey for obtaining the pass rates of the rules}

We designed a questionnaire to obtain relevant information for determining the pass rates of the fall-related QIs. The pass rate 
of a rule is the proportion of times the rule was actually followed when it should have been followed. Consider for example the (simplified) rule "IF an elder reports a history of $\geq 2$ falls in the past year, THEN the GP should document receipt of an eye exam in the past year." Its pass rate is the number of times an eye exam in the past year was documented divided by the number of times an elder reports a history of $\geq 2$ falls in the past year. Hence, a pass rate of $50 \%$ means fall documentation was performed in half of the cases that it should have been performed according to the rule.

The questionnaire was structured in two parts. The first part elicited information regarding the participants' general demographics and medical conditions. The information gathered consisted of many variables including gender, age, polypharmacy (defined as using 3 or more medications), and risk of functional decline as measured by the Identification of Seniors at Risk tool for Primary Care (ISAR-PC), which ranges between 0 and 9.5 and where a score $\geq 2$ indicates increased risk for functional decline [20].

The second part of the questionnaire covered questions to test whether the QI applies to the patient and whether his or her GP undertook the required actions.

The most important information for testing the applicability of the rule (i.e., whether the IF-part of the rule is true) included: the number of falls in the previous 12 months; having worsening difficulty with ambulation, balance, or mobility; whether the patient attended the emergency department (for example due to fracture) or visited the GP due to a fall; and whether they used walking aids or specific medications (e.g., benzodiazepine).

To evaluate the "THEN"-part (actions) of a rule, there were questions about: whether the GP proactively asked the patients if they sustained a fall in the previous 12 months; whether there were any referrals from the GP to the specialist or other caregiver within the period 3 months prior to, and 3 months after, the fall; and whether the GP took any (other) action regarding the fall(s). For example, a clinical rule related to benzodiazepine states: "IF a vulnerable elder reports a history of $\geq 2$ falls (or one fall for which the elder visits the general practitioner) in the past year and is taking a benzodiazepine, THEN the general practitioner should document a discussion of related risks and assistance offered to reduce/discontinue benzodiazepine use." The patients were asked to indicate if they received advice regarding benzodiazepine use shortly before the fall or within the period of 3 months after the fall. Data about advice regarding modifications at home to reduce fall hazards, exercise therapy, and walking aid evaluation or use were also gathered in the same way.

Three experts (one medical informatician (SE), a geriatrician (SR), and a nurse (MvR)) evaluated the questionnaire on completeness and whether the questions were comprehensible for elders.

\section{Cross-validation of documentation of self-reported falls with the medical record}

Since the International Classification of Primary Care (ICPC) coding system does not have any coding available for falls, we used free text search in the EMR to cross-validate the selfreported falls.

For this purpose, we used the SOAP (subjective, objective, assessment, and plan) notes, in the medical records used at general practices in the Netherlands. For all patients who responded to our questionnaire, we extracted their anonymized medical records between 2010 and 2012 in which any Dutch word corresponding to the following English words were present in the notes: "fall", "trauma", "crack", "rupture", "slipped", "tripped", "fracture", "bruise", "balance", "gait", or "mobility problems". Next, we selected those records that were registered over a period of 12 months prior to the date when the questionnaire was filled out by the patient. We inspected documentation in two broad categories of groups. The first is the category of patients for which we did not expect much documentation. This consists of the following patient groups: patients that sustained at most one fall for which they did not visit the GP (group A1) and non-fallers or those reported that GP did not proactively ask them about falls (group A2). The second category includes patients for which we expected a large degree of documentation. These groups consist of patients who fell at least twice or saw the GP or the Emergency Department for a fall (group B1) and patients who fell and say the GP asked them about falls (group B2).

\section{Data analysis}

Our main outcome measure was pass rates of the rules, which reflects the degree of adherence to the rules. To calculate the pass rates per rule, we divided the number of times the rule was followed by the number of times it should have been followed. For each rule, we used univariate logistic regression to estimate the association between the ISAR-PC score, as a proxy for vulnerability, and adherence to the rule ( 1 if followed and 0 otherwise).

For demographic data, we describe normally distributed continuous variables using the mean and standard deviation and test them with the $t$ test. Non-normally distributed variables are described by the median and the interquartile range (IQR), and tested by the Mann-Whitney $U$ test. Binary variables are described by proportions, and tested using the proportion test.

\section{Cross-validation analysis}

The resulting records were checked manually by a researcher to ascertain whether the documentation was indeed fall- 
Table 1 Baseline characteristics of study cohort

\begin{tabular}{|c|c|c|c|c|c|c|}
\hline \multirow{3}{*}{$\begin{array}{l}\text { Characteristic } \\
\text { Age }^{\mathrm{a}} \text {, mean (SD) }\end{array}$} & \multirow{2}{*}{\multicolumn{2}{|c|}{$\frac{\text { Number of participants }}{(N=950)}$}} & \multirow{2}{*}{\multicolumn{2}{|c|}{$\begin{array}{l}\text { Fallers } \\
(N=209)\end{array}$}} & \multirow{2}{*}{\multicolumn{2}{|c|}{$\frac{\text { Non-fallers }}{(N=741)}$}} \\
\hline & & & & & & \\
\hline & 77.7 & $(6.1)$ & 78.8 & $(6.4)$ & 77.3 & $(5.9)$ \\
\hline 74 years or younger, no. (\%) & 343 & $(36)$ & 68 & (33) & 262 & $(38)$ \\
\hline $75-84$ years, no. $(\%)$ & 432 & $(45)$ & 90 & (43) & 315 & $(46)$ \\
\hline 85 years or older, no. (\%) & 168 & (18) & 50 & (24) & 102 & (15) \\
\hline Missing data, no. (\%) & 7 & (1) & 1 & $(0)$ & 5 & (1) \\
\hline Gender: male, no. $(\%)$ & 410 & (43) & 78 & (37) & 314 & $(46)$ \\
\hline Polypharmacy $^{\mathrm{a}},(\geq 3)$ no. (\%) & 571 & $(60)$ & 143 & $(68)$ & 393 & $(57)$ \\
\hline ISAR-PC $^{\mathrm{a}}$, median [IQR] & 2.5 & {$[0-4.5]$} & 3 & {$[2.5-5]$} & 2.5 & {$[0-3]$} \\
\hline
\end{tabular}

No number, $S D$ standard deviation

${ }^{\text {a }}$ Variables for which the $p$ value of the difference between fallers and non-fallers is $\leq 0.05$ related, and whether it also contained the reason(s) for falling. We classified two levels of documentation for each patient:

1. Complete documentation: The fall history and the circumstances of falls, as well as the context (and preferably risk factors for fall/evaluation/plan) are documented.

2. Semi-complete documentation: A brief fragment or word from which we could infer that the patient sustained a fall yet without a complete history.

Note that an isolated word like "crack/fracture" was not considered as fall documentation, because one cannot infer if the fracture was due to a fall. The percentage of each level was then calculated.
All statistical analyses were performed by using the R statistical software environment version 2.11.1 (R Foundation for Statistical Computing, Vienna, Austria).

\section{Results}

Our cohort consisted of 950 patients aged 70 years or older who responded to our questionnaire (response rate $55.9 \%$, 950/1700). Table 1 shows patient characteristics of the study sample. In total, $22 \%$ (209) of the respondents reported that they sustained falls during the previous 12 months. Of these, 103 ( $49.3 \%$ of fallers and $10.8 \%$ of the total) reported two or more falls.

Table 2 Pass rates of fall-related QIs

\begin{tabular}{|c|c|c|}
\hline & $\begin{array}{l}\text { Number of eligible patients } \\
\text { among } 950 \text { elderly patients (\%) }\end{array}$ & $\begin{array}{l}\text { Pass rate } \% \text {, } \\
(95 \% \mathrm{CI})\end{array}$ \\
\hline $\begin{array}{l}\text { 1. IF a (V) E reports a history of } \geq 2 \text { falls } \mathrm{s}^{\mathrm{a}} \text { in the past year, THEN the GP should } \\
\text { document a basic fall history. }\end{array}$ & $160(17)$ & $33.8(26.6-41.7)$ \\
\hline $\begin{array}{l}\text { 2. IF a (V) E reports a history of } \geq 2 \text { falls } \mathrm{a} \text { in the past year, THEN the GP should } \\
\text { document receipt of an eye exam in the past year, or evidence of visual acuity testing. }\end{array}$ & $160(17)$ & $33.8(26.6-41.7)$ \\
\hline $\begin{array}{l}\text { 3. IF a (V) E reports a history of } \geq 2 \text { falls } \mathrm{a} \text { in the past year, or has worsening } \\
\text { difficulty with ambulation, balance, or mobility, THEN the GP should } \\
\text { document a basic gait, balance, and strength evaluation. }\end{array}$ & 279 (29) & $25.1(20.2-30.7)$ \\
\hline $\begin{array}{l}\text { 4. IF a (V) E reports a history of } \geq 2 \text { falls } \mathrm{a} \text { in the past year, THEN the GP should } \\
\text { document an assessment of cognitive status. }\end{array}$ & $160(17)$ & $16.9(11.6-23.8)$ \\
\hline $\begin{array}{l}\text { 5. IF a (V) E reports a history of } \geq 2 \text { falls } \mathrm{a} \text { in the past year, THEN the GP should document } \\
\text { an assessment and modification of home hazards recommended in the past year }\end{array}$ & $160(17)$ & $18.1(12.6-25.2)$ \\
\hline $\begin{array}{l}\text { 6. IF a (V) E reports a history of } \geq 2 \text { falls } \mathrm{a} \text { in the past year and is taking a } \\
\text { benzodiazepine, THEN the GP should document a discussion of related risks } \\
\text { and assistance offered to reduce/discontinue benzodiazepine use. }\end{array}$ & $35(4)$ & $48.6(31.7-65.7)$ \\
\hline $\begin{array}{l}\text { 7. IF a (V) E demonstrates decreased balance AND does not have an assistive } \\
\text { device, THEN an evaluation/prescription for an assistive device should be offered. }\end{array}$ & 154 (16) & $18.2(12.6-25.4)$ \\
\hline $\begin{array}{l}\text { 8. IF a (V) E reports a history of } \geq 2 \text { falls } \mathrm{a} \text { in the past year AND has an assistive } \\
\text { device, THEN there should be documentation of an assistive device review. }\end{array}$ & $95(10)$ & $22.1(14.5-32.0)$ \\
\hline $\begin{array}{l}\text { 9. IF a (V) E is found to have a problem with gait, balance, or strength, THEN } \\
\text { there should be documentation of a structured/supervised exercise program offered. }\end{array}$ & $214(23)$ & $13.6(9.4-19.0)$ \\
\hline
\end{tabular}

( $V$ ) $E$ (vulnerable) elder, $G P$ general practitioner

${ }^{a}$ Or 1 fall for which the elder visits the general practitioner 
In total, 160 patients $(16.8 \%)$ indicated that they had sustained two or more falls, or one fall for which they visited the emergency department or the GP. Only 101 patients $(10.6 \%)$ of the respondents indicated that their GP had proactively asked them whether they sustained a fall during the previous 12 months. Among 681 patients with ISAR-PC $\geq 2$, which is an indication for increased risk of functional decline, there were 78 who were asked (11.5\%). Among 346 patients with ISAR-PC $\geq 3$, there were 45 who were asked ( $13 \%$ ).

Table 2 shows the pass rates per QI in the whole cohort, which varied between 13.6 and $48.6 \%$ with the lowest and highest scores, respectively, for "offering structured/ supervised exercise program" and the "benzodiazepine advice".

Figure 1 shows the relationship between the ISAR-PC score and adherence to the rules. The lines are obtained by (locally weighted scatterplot) smoothing. Each legend displays the odds ratio and the respective $p$ value as estimated by the logistic regression model. For seven out of nine QIs, the association was positive, four of which (Q1, Q5, Q6, Q7) with a statistically significant association. These are shown in the figure having legends with boxes around them.

\section{Cross-validation}

After automatically selecting the records in the EMR, we identified 461 records, belonging to 326 unique patients, containing fall-related words documented in the period of 365 days prior to the date when the patient filled his or her questionnaire. Table 3 shows the result of the cross-validation by testing the two conditions.

\section{Discussion}

Based on a patient survey, our results show that the adherence to the ACOVE quality indicators on falls and mobility disorders in the Netherlands were low, and all had pass rates below $50 \%$. The rule pertaining to the evaluation and discontinuation of potentially harmful medications in patients who
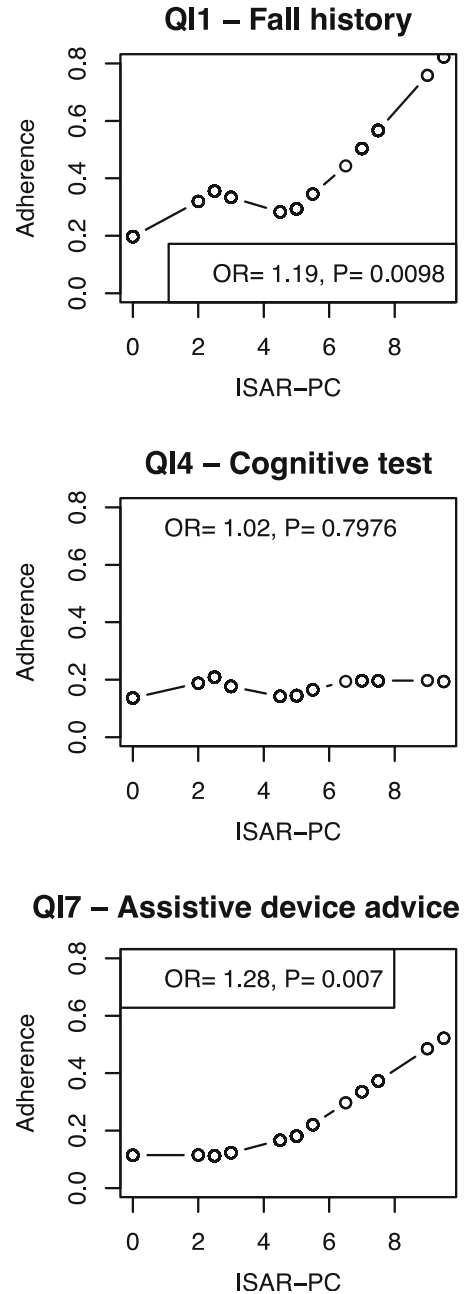
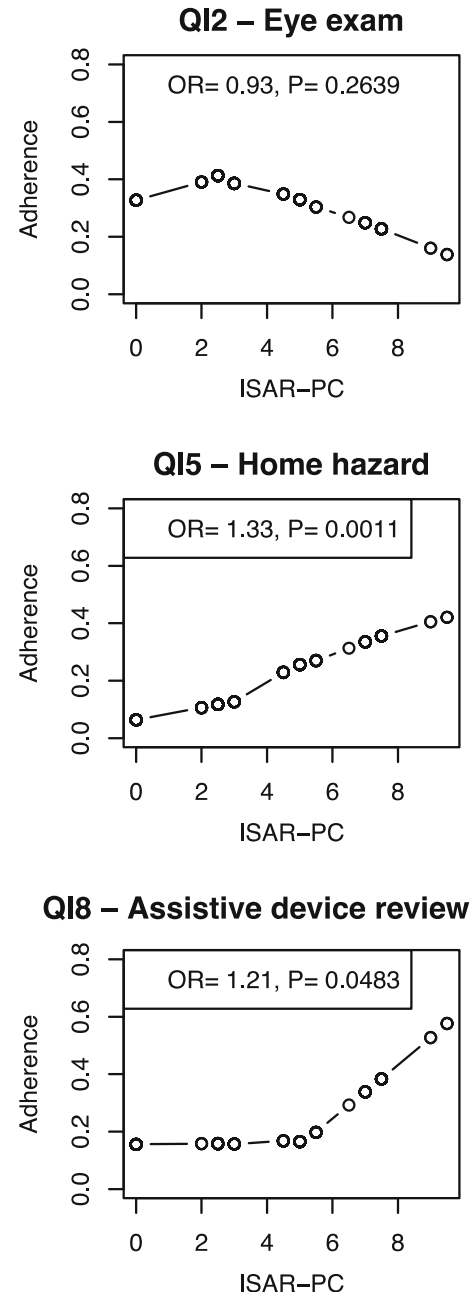
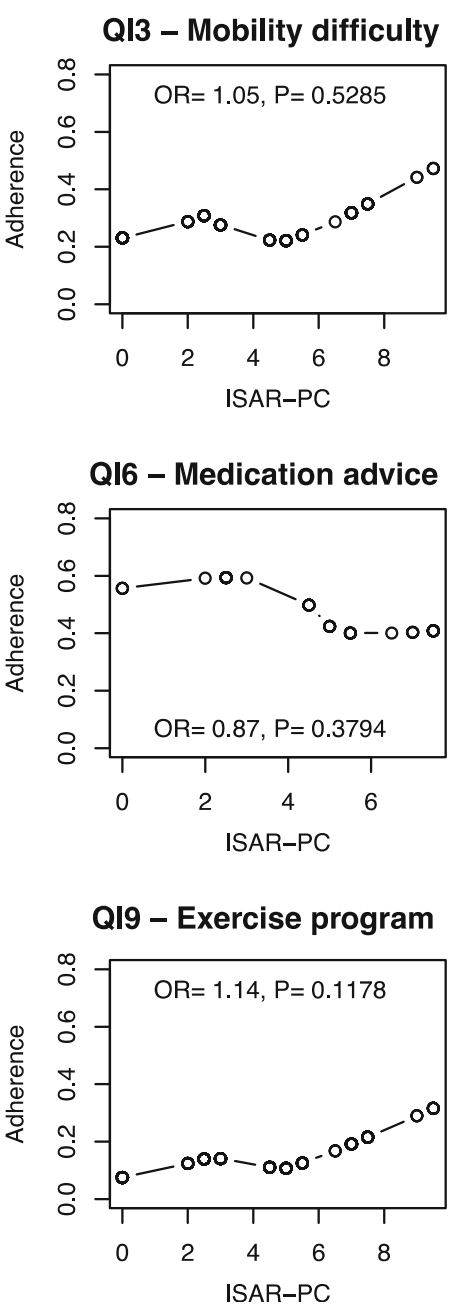

Fig 1 Smoothed lines show the association between ISAR-PC and adherence to the rules. Each legend displays the odds ratio and its $p$ value. Legends with boxes indicate statistically significant odds ratios 
Table 3 The results of the cross-validation

\begin{tabular}{|c|c|c|c|}
\hline Patient group $(N, \%$ out of 950$)$ & $\begin{array}{l}\text { Semi-complete } \\
\text { documentation }\end{array}$ & $\begin{array}{l}\text { Complete } \\
\text { documentation }\end{array}$ & $\begin{array}{l}\text { Total } \\
\text { documentation }(\%)\end{array}$ \\
\hline $\begin{array}{l}\text { Group A1: Sustained no or at most one fall for which they did not visit the GP } \\
(N=790,83.2 \% \text { of } 950)\end{array}$ & 24 & 8 & $32 / 790(4.1 \%)$ \\
\hline $\begin{array}{l}\text { Group A2: Having no falls or reported that GP did not proactively ask about falls } \\
(N=890,93.7 \% \text { of } 950)\end{array}$ & 24 & 19 & $43 / 890(4.8 \%)$ \\
\hline $\begin{array}{l}\text { Group B1: Reported two or more falls, or one fall for which they visited the } \\
\text { Emergency Department or the GP }(N=160,16.8 \% \text { of } 950)\end{array}$ & 19 & 18 & $37 / 160(23.1 \%)$ \\
\hline $\begin{array}{l}\text { Group B2: Having one or more falls and reported that the GP proactively asked } \\
\text { about the fall }(N=60,6.3 \% \text { of } 950)\end{array}$ & 12 & 10 & $22 / 60(36.7 \%)$ \\
\hline
\end{tabular}

Groups A1, A2, B1, and B2 are specified in the flowchart in Fig. 2. Note that the groups are not mutually exclusive

sustained a fall had the highest adherence among the nine QIs. The rule pertaining to the documentation of offering an exercise program for elders with mobility problems had the lowest adherence. In addition, our results show that GP adherence to the rules tended to increase with increased patient vulnerability.

Of the community-dwelling seniors 70 years or older, about $11 \%$ reported that their GP had proactively asked them whether they sustained a fall during the previous 12 months. Of these patients, $60 \%$ had fallen in the past year.

Finally, we showed that the actual EMR documentation pertaining to falls was poor (23.1\% of patients). Even for those patients who sustained a fall and reported that the GP had asked them about falls, less than $40 \%$ of them had fall documentation. One should however keep in mind that the quality indicators are largely based on expert opinion, because there is paucity in interventional studies that show the validity of the QIs for actual fall prevention. Hence, healthcare providers may not assign high importance to all QIs.

This is the largest study of the evaluation of the quality of fall and instability detection and management of general practitioners in Europe using the nine ACOVE fall QIs. Although the response rate was as high as $55.9 \%$, respondents may differ from non-respondents. However, we have previously investigated the differences among these groups in the same population [21]. On average, the non-respondents were somewhat more cognitively and functionally impaired, but these differences were largely offset by a large group of healthy elders, which were probably uninterested in participating. Although patient self-report may be limited by recall bias, the cross-validation showed that patient self-report exceeded the actual EMR documentation by GPs. Therefore, it is likely that the questionnaires adequately reflect GP actions.

Our findings on low adherence to fall-related QIs are similar to those of a chart and interview-based study in the US by Rubinstein and colleagues [17], although the study approaches somewhat differed. One study in the UK addressed only two ACOVE fall QIs in the primary care setting [22] as the remaining QIs from the ACOVE fall set were either not valid for the UK or were difficult to implement. In the latter study, the data were derived from self-reports at interview. The
Fig 2 Flowchart of patients and the documentation percentages for the groups A1, A2, B1, and B2

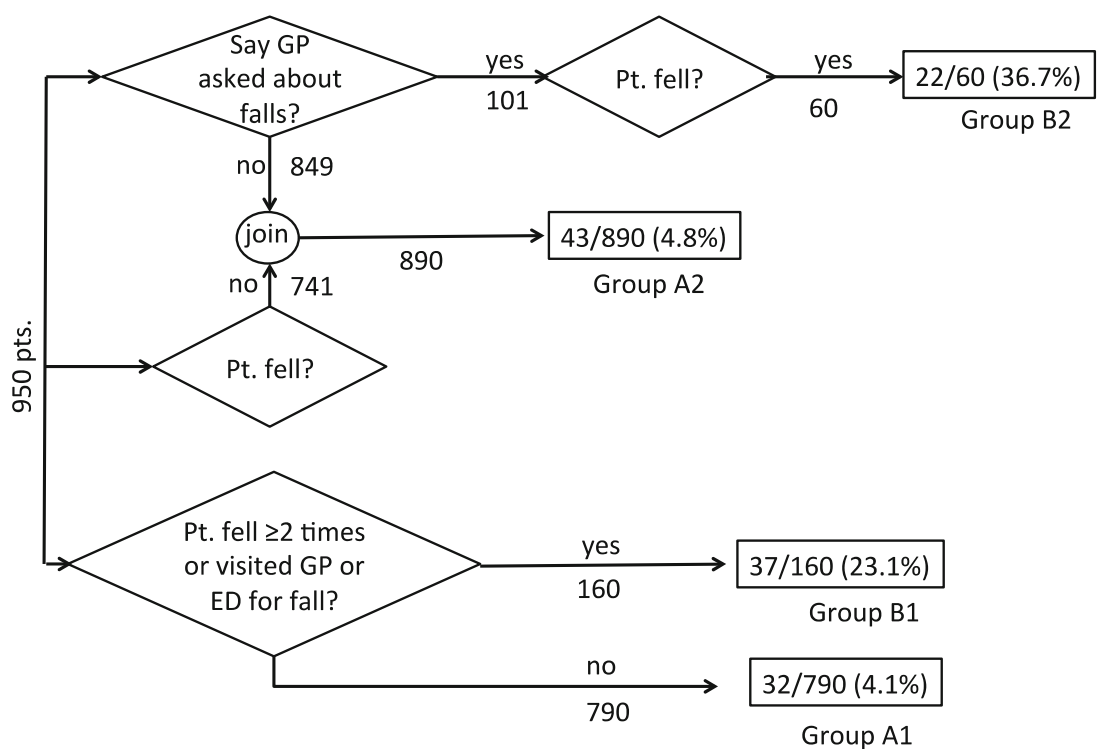


mean pass rates for the two QIs were also low at $43.5 \%$ (CI 36.5-50.6).

Adherence significantly increased with increase in vulnerability for the rules on documentation of fall history; on documentation of assessment and modification of home hazards; on offering an evaluation or prescription of an assistive device; and on documentation of an assistive device review. Only the rules pertaining to the documentation of an eye exam and to the documentation of a discussion on adjusting benzodiazepine use had negative, albeit not significant, association between vulnerability and adherence. Notwithstanding the possibility that these may be chance findings, it is possible that GPs perceive little added value for following these rules for the very vulnerable. In addition, measuring adherence for the eye exam rule may not be very reliable because exams are often performed by an optician instead of the GP (see below). Another possibility is that GPs do not directly associate vision problems with an increased risk of falling. For the benzodiazepine rule, it is possible that GPs accept the tradeoff between the advantages and disadvantages of using the medication for the very vulnerable, especially if they have been using the medication for a long time. Finally, it is also possible that GPs tend to avoid a complex discussion about the pros and cons of discontinuing benzodiazepine use.

In our study, we may have underestimated actual EMR fall documentation, because we were not able to include information from hospital discharge letters, and it is common practice for Dutch GPs to use these letters as documentation without transcribing them into their SOAP notes. However, subsequent fall-preventive treatment and management would still be needed to be documented in the EMR. It is still possible that information on delivered care for falls could have been lacking in the GPs' EMR, while the care might have been delivered and documented in another setting and therefore the GPs did not document it in the EMR. For example, eye exams are for free in the optician's office in the Netherlands, hence lack of documentation in the GP office does not necessarily indicate lack of adherence to the respective rule. Therefore, a better integration of information in the shared care processes is needed. This integration could also be further supported if a fall would have been added to the coding system, as this encourages its recording and retrieval in the system.

Nevertheless, as Rubenstein and colleagues indicated [17], the fact that patients reported only a few of the examination components to have been performed suggests that the problem is in performance, not just in documentation. There is evidence about the effectiveness of the follow-up assessment in reducing subsequent falls [15]. Therefore, one should strive to improve this performance proactively. Computerized clinical decision support systems may play an important role in this respect.

\section{Conclusion}

Our findings demonstrate an insufficiency in the quality of evaluation and management of falls in community-dwelling older persons in the Netherlands as measured by the fallrelated ACOVE quality indicators. For most indicators, adherence increased with the increase in the risk of functional decline.

Acknowledgments This research was funded by ZonMw (The Netherlands Organization for Health Research and Development) by a grant for the PROFIT (no. 300020010) project.

\section{Conflicts of interest None.}

Open Access This article is distributed under the terms of the Creative Commons Attribution-NonCommercial 4.0 International License (http:// creativecommons.org/licenses/by-nc/4.0/), which permits any noncommercial use, distribution, and reproduction in any medium, provided you give appropriate credit to the original author(s) and the source, provide a link to the Creative Commons license, and indicate if changes were made.

\section{References}

1. Campbell AJ, Reinken J, Allan BC, Martinez GS (1981) Falls in old age: a study of frequency and related clinical factors. Age Ageing 10(4):264-270

2. Hartholt KA, van Beeck EF, Polinder S et al (2011) Societal consequences of falls in the older population: injuries, healthcare costs, and long-term reduced quality of life. J Trauma 71(3):748-753

3. Tinetti ME, Speechley M, Ginter SF (1988) Risk factors for falls among elderly persons living in the community. N Engl J Med 319(26): 1701-1707

4. Scheffer AC, Schuurmans MJ, van Dijk N, van der Hooft T, de Rooij SE (2008) Fear of falling: measurement strategy, prevalence, risk factors and consequences among older persons. Age Ageing 37(1):19-24

5. Rubenstein LZ (2006) Falls in older people: epidemiology, risk factors and strategies for prevention. Age Ageing 35(2):ii37-ii41

6. van Nieuwenhuizen RC, van Dijk N, van Breda FG et al (2010) Assessing the prevalence of modifiable risk factors in older patients visiting an ED due to a fall using the CAREFALL Triage Instrument. Am J Emerg Med 28(9):994-1001

7. Woolcott JC, Richardson KJ, Wiens MO et al (2009) Meta-analysis of the impact of 9 medication classes on falls in elderly persons. Arch Intern Med 169(21):1952-1960

8. Askari M, Eslami S, Scheffer AC et al. (2013) Different riskincreasing drugs in recurrent versus single fallers: are recurrent fallers a distinct population? Drugs \& aging. (In press)

9. Tinetti ME, Inouye SK, Gill TM, Doucette JT (1995) Shared risk factors for falls, incontinence, and functional dependence. Unifying the approach to geriatric syndromes. JAMA 273(17):1348-1353

10. Stel VS, Smit JH, Pluijm SM, Lips P (2003) Balance and mobility performance as treatable risk factors for recurrent falling in older persons. J Clin Epidemiol 56(7):659-668

11. Askari M, Wierenga PC, Eslami S, Medlock S, de Rooij SE, AbuHanna A (2011) Assessing quality of care of elderly patients using the ACOVE quality indicator set: a systematic review. PLoS One 6(12):e28631 
12. van der Ploeg E, Depla MF, Shekelle P, Rigter H, Mackenbach JP (2008) Developing quality indicators for general practice care for vulnerable elders; transfer from US to the Netherlands. Qual Saf Health Care 17(4):291-295

13. Close JC, Hooper R, Glucksman E, Jackson SH, Swift CG (2003) Predictors of falls in a high risk population: results from the prevention of falls in the elderly trial (PROFET). Emerg Med J 20(5):421-425

14. El-Khoury F, Cassou B, Charles MA, Dargent-Molina P (2013) The effect of fall prevention exercise programmes on fall induced injuries in community dwelling older adults: systematic review and meta-analysis of randomised controlled trials. BMJ 347:f6234

15. Chang JT, Morton SC, Rubenstein LZ et al (2004) Interventions for the prevention of falls in older adults: systematic review and metaanalysis of randomised clinical trials. BMJ 328(7441):680

16. Askari M, Westerhof R, Eslami S, Medlock S, de Rooij SE, AbuHanna A. (2013) A combined disease management and process modeling approach for assessing and improving care processes: a fall management case-study. Int J Med Inform

17. Rubenstein LZ, Solomon DH, Roth CP et al (2004) Detection and management of falls and instability in vulnerable elders by community physicians. J Am Geriatr Soc 52(9):1527-1531
18. Askari M, Wierenga PC, Eslami S, Medlock S, de Rooij SE, AbuHanna A (2012) Studies pertaining to the ACOVE quality criteria: a systematic review. Int J Qual Health Care 24(1):80-87

19. Saliba D, Elliott M, Rubenstein LZ et al (2001) The vulnerable elders survey: a tool for identifying vulnerable older people in the community. J Am Geriatr Soc 49(12):1691-1699

20. Suijker JJ, Buurman BM, ter Riet G et al (2012) Comprehensive geriatric assessment, multifactorial interventions and nurse-led care coordination to prevent functional decline in community-dwelling older persons: protocol of a cluster randomized trial. BMC Health Serv Res 12:85

21. Van Dalen MT, Suijker JJ, MacNeil-Vroomen J, van Rijn M, Moll van Charante EP, de Rooij SE, Buurman BM (2014) Self-report of healthcare utilization among community-dwelling older persons: a prospective cohort study. PLoS ONE 9(4):e93372. doi:10.1371/ journal.pone.0093372

22. Steel N, Bachmann M, Maisey S et al (2008) Self reported receipt of care consistent with 32 quality indicators: national population survey of adults aged 50 or more in England. BMJ 337:a957 